\title{
Differences in the tooth whitening effect between strawberry juice and apple juice in-vitro
}

\author{
Stephanie*, Ayu Trisna Hayati*, Endang Sukartini* \\ *Department of Conservative Dentistry Faculty of Dentistry Universitas Padjadjaran, Indonesia
}

\begin{abstract}
Bleaching is the tooth whitening by applying chemical materials oxidizing the organic tooth pigmentation and creating smaller and lighter molecules. Commonly used in the tooth bleaching is hydrogen peroxide. Strawberry and apple contain hydrogen peroxide and ellagic acid which will bond with an unsaturated bond of the tooth pigmentation. The purpose of this research was to finding out and measuring the tooth whitening level and effectivity between the strawberry and apple juice. The type of this research was a true experimental (in-vitro), using 30 samples of maxillary premolars with cutted radicular until the CEJ. Samples were divided into 3 groups (immersed in strawberry juice; apple juice; and mineral water); with three times daily immersion in one week. The tooth colour level was measured using a spectrophotometer. Data were analyzed using the one-way ANOVA and LSD test. The results showed significant differences among all groups. Normality test showed the variance between homogenous groups, with the $p$-value of $0.198(p \geq 0.05)$. The one-way ANOVA test results showed a significance value (0.000), indicated a significant degree of the tooth whitening level between all groups. The LSD test results showed that the tooth whitening level in group I (immersed in strawberry juice) was significantly different to group II (immersed in apple juice) and group III (immersed in mineral water), with a significance value of 0.01 and $0.00(p \leq 0.05)$. The tooth whitening level in group II was significantly different from group III, with a significance value of $0.03(p \leq 0.05)$. There were differences in the tooth whitening level between immersion in strawberry juice, apple juice, and mineral water, with the most effective tooth whitening level found in the strawberry juice immersion.
\end{abstract}

Keywords: Bleaching, ellagic acid, strawberry juice, apple juice, tooth whitening level

\section{INTRODUCTION}

Aesthetical issues included appearances, such as hairstyles, fashion, and even aesthetical aspects on orofacial appearances for psychological, social, occupational, and other reasons have become the public concerned in recent years. Beautiful teeth are very influential for individual appearances because teeth are the most prominent element when someone is smiling, laughing, and talking. Any tooth abnormalities can diminish the beauty of a smile in the form of discoloration and malposition. ${ }^{1}$

Teeth can discoloured either extrinsically or intrinsically. Consumption of tea, coffee, and cigarettes will make the color of the teeth turned yellow or darker. The aging process will increase the tooth discoloration due to the formation of secondary dentine. Patients look for ways to restore the tooth color brighter, whiter, and 
thus increasing their confidence. ${ }^{2,3,4}$ Bleaching, microabrasion, macroabrasion, veneering, and porcelain crowns are treatment techniques that will restore the tooth discolouration. Bleaching is the most popular treatment due to its effectiveness in the tooth whitening process. Bleaching materials commonly used are hydrogen peroxide and carbamide peroxide.

The success of a bleaching treatment was determined by the active compounds used, the concentration, and the time interval..2,4,5 Information regarding technology, food, and nutrition is growing rapidly, especially regarding the consumption of fruits and vegetables in the past few years. Many benefits obtained from the consumption of fruits and vegetables are the effects of nutritional, vitamin, and mineral contained in fruits and vegetables. ${ }^{6}$

The results of research conducted by Song and Palmer in 2008 suggested that hydrogen peroxide $\left(\mathrm{H}_{2} \mathrm{O}_{2}\right)$ was found in fruits and vegetables during the process of their metabolism. Hydrogen peroxide $\left(\mathrm{H}_{2} \mathrm{O}_{2}\right)$ is a powerful oxidizing agent used in the bleaching process. Many similar studies have been developed recently in the search for alternative natural teeth whitening compounds relatively safe (minimum side effect) for the oral cavity tissues. ${ }^{4,5,7}$

Schenk at the California State Science Fair in 2007 described several types of fruits and vegetables with tooth whitening potentials, which were carrots, oranges, pears, apples, strawberries, and lemons. Strawberry and apple contain ellagic acid $\left(\mathrm{C}_{14} \mathrm{H}_{6} \mathrm{O}_{8}\right) .8$ Ellagic acid has potentials $\mathrm{OH}$ group as a strong oxidizing agent, as well as hydrogen peroxide. The results of a study conducted by Reksodiputro et al. in 2004 showed that the effect of bleaching of tooth enamel on the exposure. ${ }^{9}$ The purpose of this research was to finding out and measuring the tooth whitening level and effectivity between the strawberry and apple juice.

\section{METHODS}

This research was the pure experimental research (true experimental) in-vitro. The study population was the maxillary premolar teeth of the extraction result for orthodontic purposes in the dentists' private practice of the Northern Bandung area (Sukajadi, Bandung, Coblong, Cidadap and Cicendo districts), from February to May 2011. The sample criteria for this study were as follows: intact teeth; caries-free; no restoration; perfectly formed radicular; tooth extraction period from February to May 2011; tooth extraction results immersed in $0.9 \% \mathrm{NaCl}$ physiological.

As much as 30 maxillary premolar teeth met the sample criteria. Independent variables in this study were strawberry juice and apple juice. Dependent variable in this study was the tooth whitening degree. Controlled variables in this study were type and ripeness of fruit used; $\mathrm{pH}$ and volume of strawberry juice and apple juice; $\mathrm{pH}$ and type of the artificial saliva; type of tooth used; and spectrophotometer used. Moderator variables in this study were temperature; changes of $\mathrm{pH}$ value in artificial saliva, strawberry juice, and apple juice; and the tooth position during the colour measurement with a spectrophotometer. Random variables in this study were the teeth calcification, weight, shape, size, and color basis.

The operational definitions used were as follows: Dental specimens (specimens of maxillary premolar teeth) cut into the CEJ boundary, and the tooth piece covered with clear nail polish; Artificial saliva was a solution of $\mathrm{H}_{2} \mathrm{O}, \mathrm{NaCl}, \mathrm{KCl}$, $\mathrm{Na}_{2} \mathrm{HPO}_{4} \mathrm{H}_{2} \mathrm{O}, \mathrm{NaHCO}_{3}, \mathrm{KSCN}$, and urea, prepared as the replacement of the natural saliva in the oral cavity, stored in an incubator at $37^{\circ} \mathrm{C}$; Strawberry juice was a concentrated solution of 100 grams of smoothed strawberries (grinded using a blender without any additional water and sweetener); Apple juice was a concentrated solution of 100 grams of smoothed apples (grinded using a blender without any additional water and sweetener); Tooth discoloration was a color change occurred on the surface of a dental specimen measured using a spectrophotometer with a precision of 0.01 , and the results manually recorded by the operator.

Tools used in this study were spectrophotometer, Incubator, thirty labeled plastic containers, scale, blender, measuring cup, pipette, stationery kits, polishing brush, micromotor, stopwatch, and ultrasonic scaler. Materials used in this study were 30 maxillary premolar teeth immersed in $0.9 \%$ physiological $\mathrm{NaCl}$ solution, $100 \mathrm{gr}$ of strawberries, $100 \mathrm{gr}$ of apples, mineral water, nail polish, AFNOR type artificial saliva (made by Biochemistry Laboratory of 
Faculty of Medicine Universitas Padjadjaran). The research procedures were presented in Figure 3.

Data generated from the measurement results with spectrophotometer were statistically analyzed using ANOVA test by statistical software.

\section{RESULTS}

The result showed that the discolouration of dental specimens before and after treatment in the form of statistical data consisted of the minimum value, maximum value, mean, median, and standard deviation was presented in Table 1. The average tooth discolouration in group I was 2.515, group II was 1.448, and group III was 0.570 . Differences of tooth discolouration in each group were described in Figure 1.

Figure 1 showed that the average value of different teeth whitening degrees between all specimen groups. The average value of the teeth whitening degrees of group III was lower than the other groups, with the highest difference value was found in group I. This result showed that the

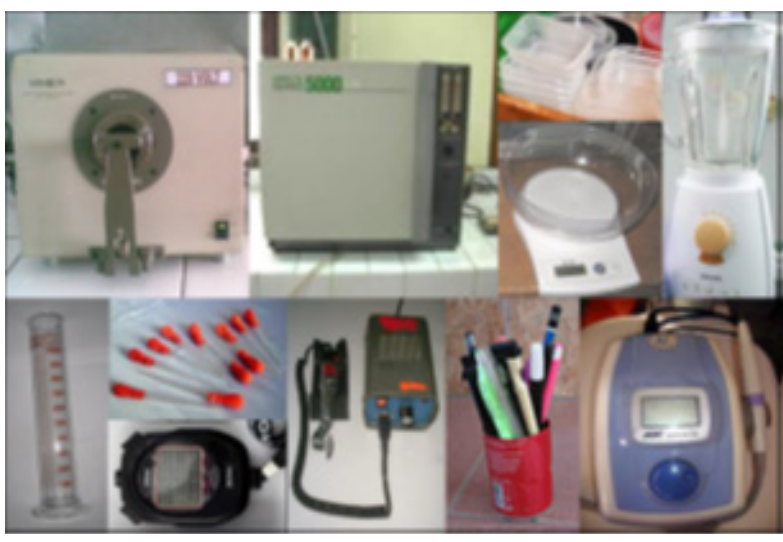

Figure 1. (a) Spectrophotometer; (b) Incubator; (c) Plastic containers; (d) Scale; (e) Blender; (f) Measuring cup; (g) Pipettes; (h) Stopwatch; (i) Micromotor; (j) Stationery; (k) Ultrasonic scaler

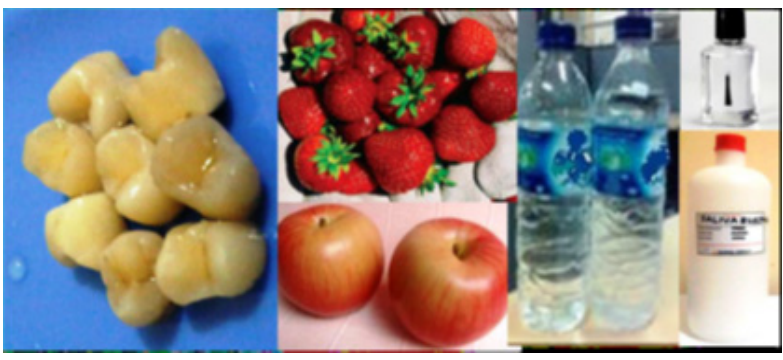

Figure 2. (a) Maxillary premolar teeth; (b) Strawberries; (c) Apples; (d) Mineral water; (e) Nail polish; (f) Artificial saliva lowest teeth whitening degree was found in group III and the highest was found in group I.

Data of the teeth whitening measurements were analyzed using one-wayANOVA test. Normality test (Shapiro-Wilk test) and homogeneity test (Levene test) were performed as a prerequisite of the one-way ANOVA test. Normality and homogeneity test results can be seen in Table 2 . Normality test results showed the $p$-value (countable $a$ ) in each group was above 0.05 . This result showed that the value of different teeth whitening degrees in all groups have a normal distribution. Homogeneity test result of all groups showed the $p$-value (countable $a$ ) was 0.198 $(p \geq 0.05)$. This result showed the variance between homogeneous groups. Results obtained from the one-way ANOVA test were presented in Table 3.

One-way ANOVA test has a significance parameter above 0.05 . The one-way ANOVA test in

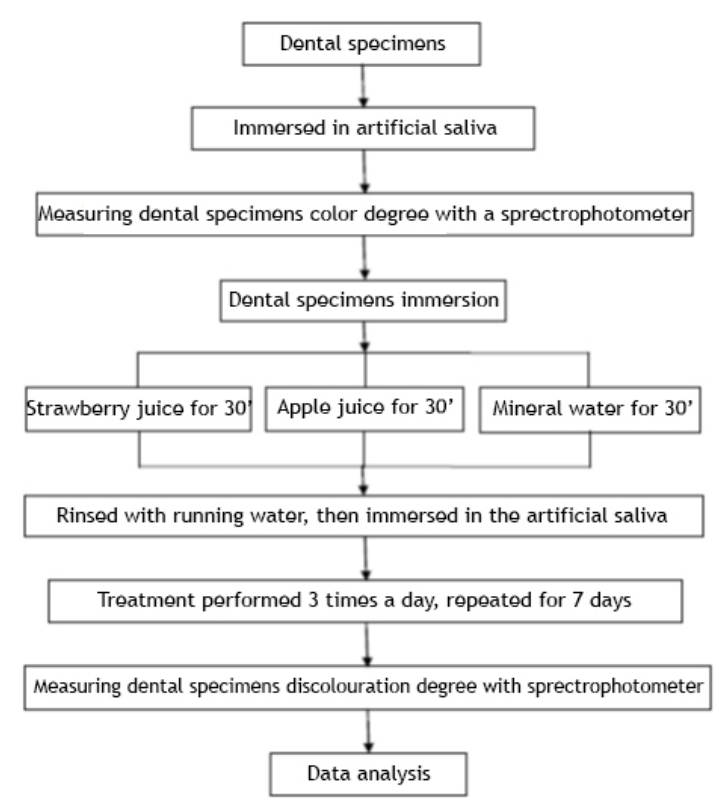

Figure 1. Average tooth whitening degrees difference in all dental specimens group before and after treatment

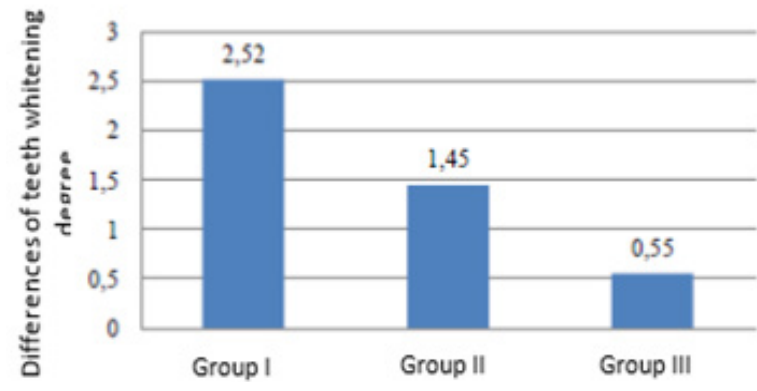

Figure 3. Research process 
Table 1. Teeth specimens discolouration degree before and after treatment

\begin{tabular}{|c|c|c|c|c|}
\hline Group & Sample number & Tooth whitening degree changes & Mean & Standard Deviation \\
\hline \multirow{10}{*}{ Group I } & 1 & 3.44 & \multirow{10}{*}{2.515} & \multirow{10}{*}{1.15441} \\
\hline & 2 & 2.66 & & \\
\hline & 3 & -0.02 & & \\
\hline & 4 & 1.81 & & \\
\hline & 5 & 3.76 & & \\
\hline & 6 & 2.41 & & \\
\hline & 7 & 3.03 & & \\
\hline & 8 & 3.82 & & \\
\hline & 9 & 1.70 & & \\
\hline & 10 & 2.54 & & \\
\hline \multirow{10}{*}{ Group II } & 11 & 2.64 & \multirow{10}{*}{1.448} & \multirow{10}{*}{0.81874} \\
\hline & 12 & 1.02 & & \\
\hline & 13 & 1.28 & & \\
\hline & 14 & 2.16 & & \\
\hline & 15 & -0.04 & & \\
\hline & 16 & 1.52 & & \\
\hline & 17 & 2.49 & & \\
\hline & 18 & 1.01 & & \\
\hline & 19 & 0.83 & & \\
\hline & 20 & 1.57 & & \\
\hline \multirow{10}{*}{ Group III } & 21 & 1.03 & \multirow{10}{*}{0.570} & \multirow{10}{*}{0.47631} \\
\hline & 22 & -0.01 & & \\
\hline & 23 & 0.31 & & \\
\hline & 24 & 1.29 & & \\
\hline & 25 & 0.27 & & \\
\hline & 26 & 1.25 & & \\
\hline & 27 & 0.01 & & \\
\hline & 28 & 0.41 & & \\
\hline & 29 & 0.48 & & \\
\hline & 30 & 0.66 & & \\
\hline
\end{tabular}

Table 2. Normality (Shapiro-Wilk) and homogeneity (Levene) test results

\begin{tabular}{lcc}
\hline Sample group & Normality test value (Shapiro-Wilk) & Homogeneity test value (Levene) \\
\hline Group I & 0.310 & \\
Group II & 0.792 & 0.198 \\
Group III & 0.275 & \\
\hline
\end{tabular}

Table 3. One-way ANOVA test results

\begin{tabular}{lccccc}
\hline & Sums of square & Degrees of freedom & Middle square & F & Significance \\
\hline Between group & 18.975 & 2 & 9.487 & 12.764 & 0.000 \\
In group & 20.069 & 27 & 0.743 & & \\
\hline Total & 39.043 & 29 & & & \\
\hline
\end{tabular}


Table 4. LSD (Least Significant Difference) test result

\begin{tabular}{ccc}
\hline Comparison & LSD test result value & Interpretation \\
\hline Group I-Group II & 0.01 & Significant \\
Group I-Group III & 0.00 & Significant \\
Group II-Group III & 0.03 & Significant \\
\hline
\end{tabular}

Notes: $a=0.05$

this study was resulting in the significance value of 0,000 , which showed that there was a significant difference in the teeth whitening degree between immersion in strawberry juice, apple juice, and mineral water (as the control group). The LSD (Least Significant Difference) test statistic test was performed to determine the significant differences between groups. The LSD test results were presented in Table 4.

The LSD test result showed that the significance parameter was above 0.05 (confidence level $=95 \%$ ). The teeth whitening degree in group I (immersion in strawberry juice) was significantly different with group II (immersion in apple juice) and with group III (immersion in mineral water) with the significance value of 0.01 and 0.00 consecutively $(p \leq 0.05)$. The teeth whitening degree in group II (immersion in apple juice) was significantly different with group III (immersion in mineral water) with the significance value of 0.03 $(p \leq 0.05)$.

\section{DISCUSSION}

Bleaching is an action of whitening the teeth by applying chemical compounds containing strong oxidizing agents. Materials commonly used in the bleaching process included hydrogen peroxide, sodium perborate, and carbamide peroxide. The oxidation reactions of hydrogen peroxide occurred by the release of $\mathrm{O}$ and $\mathrm{HO} 2$ free radicals, which will interfere with electron conjugations, as well as changing in the energy absorption in the tooth enamel organic molecules to form smaller organic molecules with a lighter colour. ${ }^{2,10-14}$

Strawberries and apples contain hydrogen peroxide which plays an important role in the metabolism process. Strawberries and apples also contain ellagic acid (C14H6O8) which has potential $\mathrm{OH}$ clusters as a powerful oxidizer in the teeth whitening process. The ellagic acid content in strawberries ranging from 0.43 to $4.64 \mathrm{mg} / \mathrm{g}$ dry weight. The ellagic acid content in apples was less than the strawberries, ranging from $0.13 \mathrm{mg} / \mathrm{g}$ dry weight. The more ellagic acid amount will produce more potential $\mathrm{OH}$ clusters as a powerful oxidizer thus make the more effective bleaching process. ${ }^{6,8,14,15}$

Ellagic acid releases the $\mathrm{OH}$ and $\mathrm{H}$ radicals which will react with the tooth enamel organic molecules and disrupt the electron conjugation, as well as changing the energy absorption in the tooth enamel organic molecules to form smaller organic molecules with a lighter colour. Ellagic acid has a slight difference molecular formula than other acids. Ellagic acid has an $\mathrm{OH}$ cluster, not a $\mathrm{COOH}$ cluster like any other acids. The electronegativity of the $\mathrm{OH}$ group was larger than the $\mathrm{COOH}$ cluster thus the $\mathrm{OH}$ group will be easier to break and react with the organic molecules of the tooth enamel. ${ }^{8}$

Statistical analysis using one-way ANOVA test showed significant differences in the teeth whitening degree between all groups. The LSD tests showed significant differences between group I, and II, group I and III, and also group II and III. Group I (immersed in strawberry juice three times a day) showed a significant difference in the teeth whitening degree compared to group III (immersed in mineral water three times a day). The result of this study showed the similar results with a study conducted by Reksodiputro et al. in 2004 and Schenk in 2007, suggested the effectivity of the tooth bleaching by strawberry juice due to the presence of hydrogen peroxide and ellagic acid in strawberries. ${ }^{7,8}$

Group II (immersed in apple juice three times a day) showed a significant difference in the teeth whitening degree compared to group III (immersed in mineral water three times a day). The result of this study showed the similar results with a study conducted by Schenk in 2007 and Aulia et al. in 2009, suggested the effectivity of the tooth bleaching by apple juice due to the presence of hydrogen peroxide and ellagic acid in apples. ${ }^{8,15}$ Group I (immersed in strawberry juice three times a day) showed a significant difference in the teeth whitening degree compared to group II (immersed in apple juice three times a day).

The results of this study may caused by the concentration of ellagic acid in strawberries was 
higher than in apples. The higher concentration of ellagic acid, the more effective the bleaching process. This statement was supported by Roberson's statement in 2006, stated that the success of a bleaching treatment was determined by the concentration of the bleaching materials. The higher concentration of the bleaching agents, the higher teeth whitening degree obtained, because the number of free radicals reacts with the teeth colouring agent and make the higher amount of smaller and lighter organic molecules. ${ }^{4}$

The results of this study showed that each specimen was experiencing different teeth whitening degree. This result occurred due to the uniformity of dental specimens used. Other influential factors including age, damage to the enamel during extraction, and fluoridated teeth. The older age of the teeth, the more formation of secondary dentine occurred thus will affecting the enamel colour transparency, or the teeth color will be seen more opaque. Teeth will absorb the light from the spectrophotometers more because of a large number of secondary dentine thus showing a lower white degree. Damage to the enamel during extraction will affect the colour absorption due to the opening dentinal tubules. The opening dentinal tubules will cause the bleaching agents react with the dentine as well, resulting in a lighter color thus will reflect more light from spectrophotometers. The bright white color shows a higher teeth whitening degree. The $\mathrm{F}$ cluster replaces the $\mathrm{OH}$ group of the tooth enamel hydroxyapatite, which has undergone fluoridation and forming fluorapatite. Fluorapatite bond was difficult to break thus the bleaching effect on this kind of tooth becomes ineffective. ${ }^{16}$

\section{CONCLUSIONS}

There was a difference in the teeth whitening effect between immersion in strawberry juice compared to apple juice in-vitro. Immersion in strawberry juice caused more effective teeth whitening compared to apple juice.

\section{REFERENCES}

1. Baum L, Phillips RW, Lund MR. Textbook of operative dentistry. $3^{\text {th }}$ ed. Philadelphia: W.B. Saunders Co.; 1997. p. 307-13.
2. Grossman LI, Oliet S, Del Rio CE. Ilmu endodontik dalam Praktek. $11^{\text {th }}$ ed. Jakarta: EGC; 1995. p. 295-301.

3. Ryan T. What You Need to Know About At-Home Bleaching. [cited 2011 Jun]; [about 2 screens]. Available from: http://www.suite101.com/ article.cfm/dental_health/16861. 1999.

4. Heymann HO, Swift EJ Jr., Ritter AV. Roberson, Sturdevant's Art and science of operative dentistry. $6^{\text {th }}$ ed. St. Louis: Mosby-Elsevier; 2006. p. 18-23.

5. Walton RE, Torabinejad M. Prinsip dan Praktik: Ilmu Endodonsia. $2^{\text {nd }}$ ed. Jakarta: EGC; 2002. p. 1-40.

6. Yulianti S, Irlansyah, Junaedi E, Mufatis. Khasiat dan manfaat buah Apel. Jakarta: AgroMedia Pustaka. p. 1-40.

7. Lu S, Song J, Campbell-Palmer L. A modified chemiluminescence method for hydrogen peroxide determination in apple fruit tissues. Sci Hort 2009 May 1;120(3):336-41.

8. Schenk LI. Teeth whitening with natural products. [cited 2011 Sep]; [about 2 screens]. Available from:http://cssf.usc.edu/ History/2007/Projects/J1830.pdf

9. Reksodiputro S. Efek jus buah stroberi terhadap pemutihan kembali permukaan email gigi [minor thesis]. Jakarta: UI; 2004. p. 24-9.

10. McLaughlin G, Freedman GA. Color atlas of tooth whitening. St. Louis: Ishiyaku Euroamerica Inc.; 1991. p. 10-30.

11. Goldstein RE, Baber DA. Complete dental bleaching. Chicago: Quintessence Publishing Co. Inc.; 1995. p. 25-32.

12. Kihn PW, Barnes DM, Romberg E, Peterson K. Clinical evaluation of $10 \%$ vs $15 \%$ carbamide tooth-peroxide whitening agents. J Am Dent Assoc 2000 Oct;131(10):1478-84.

13. Meizarini A, Rianti D. Tooth bleaching material with ADA/ISO certificate. Maj Ked Gigi (Dent J). 2005 Apr-Jun;38(2):73-6.

14. Joiner $A$. The bleaching of teeth: a review of the literature. J Dent. 2006 Aug;34(7):412-9.

15. Apandi M. Teknologi Buah dan Sayuran. Bandung: Alumni; 1984. p. 10.

16. Aulia J. Perbedaan frekuensi pemaparan jus apel kemasan terhadap pemutihan gigi [minor thesis]. Bandung: Unpad; 2009. p. 41-4.

17. Osborn JW, Ten Cate AR. Advanced dental history. $4^{\text {th }}$ ed. London: Wright; 2003. p. 25-8. 